\title{
Pesticidal paints: an integral approach to colour your imagination
}

\begin{abstract}
Pesticidal paints (PPs) have been commercially available for several years; recently they are promoted against nuisance pests that dwell on walls and ceilings. Although PPs have been suggested for the control of disease vectors since the 1940s, the concept has never gained much attention compared with Indoor Residual Spraying (IRS), which offers the same basic mode of action. Today, however, PPs are receiving renewed interest for their potential use against disease vectors. This interest can be attributed to several factors, of which we list the most important below, along with the concerns that should be addressed before this intervention tool achieves widespread application.
\end{abstract}

Keywords: pesticidal paints, formulation, slow release, microencapsulated, repellency
Volume 2 Issue I - 2018

\author{
Dipak Kumar Hazra \\ Department of Agricultural Chemicals, Bidhan Chandra Krishi \\ Viswavidyalaya, India
}

\begin{abstract}
Correspondence: Dipak Kumar Hazra, AINP on Pesticide Residue Laboratory, Department of Agricultural Chemicals, Bidhan Chandra KrishiViswavidyalaya, Directorate of Research, Research Complex Building, Kalyani-74I 235, Nadia,West Bengal, India, Email dipakipft@gmail.com
\end{abstract}

Received: December 07, 2017| Published: February 16, 2018

\section{Introduction}

Recent advances in paint technology have guided the development of novel "ready-to-use" paint formulations in which microencapsulated insecticides, or active ingredients (AIs), are embedded in the paint matrix and gradually released on the surface of the dried paint. ${ }^{1}$ It is argued that the slow-release mechanisms enable uniform AI surface concentrations with prolonged residual effect, as compared to earlier PP products using a simple admixture of AIs in standard paint formulations. ${ }^{2}$ Depending on the chemical action of the embedded AIs, PPs may display different properties, including spatial repellency, contact irritancy, toxicity, insecticide synergy, or insect growth regulation. Importantly, different AIs can be combined in a single PP to ensure different modes of action in one product.

Slow-release (Pesticidal paints) formulations seem to cope with the problem of quick degradation of insecticide on mud surfaces as well as with absorption. They are based on latex or polyvinyl acetate and can be applied to walls by spraying or brushing. Application of the paint by brushing has the advantage of being simpler and cheaper than conventional insecticide application, taking into account the long persistence of the products. However, mud walls are not very suitable for brushing, which erodes the surface; spraying covers the surface with a thin film and is preferred by vector control agencies because it is less time-consuming and more efficient. Recently an insecticidal paint effective against triatomine bugs (T. infestans) has been specially developed for spraying on mud surfaces. It is also suitable for brushon application. ${ }^{3}$ After drying, it becomes transparent and produces a thin plastic film. This product has to be mixed with water before application.

Only insecticides with a high vapour pressure can be used, because the particles have to move to the surface of the paint layer. Malathion, propoxur, pirimiphos methyl and fenitrothion are suitable. Thus $8.3 \%$ malathion emulsifiable concentrate or wettable powder added to an emulsifiable suspension consisting mainly of polyvinyl acetate, after drying, leaves a thin film containing around $13 \%$ of active ingredient that continuously migrates to the surface.

\section{Advantages}

The insecticidal paints have greater persistence and therefore are more cost-effective than conventional insecticides. One application may last up to two years, whereas standard formulations of insecticides such as the synthetic pyrethroids and Benzene hexachloride (BHC) do not last longer than a year. In a study in Brazil the cost of keeping a house free of triatomine bugs for one year was estimated at US\$29 for paint, $\$ 73$ for BHC, and between $\$ 31$ and $\$ 66$ for most common pyrethroids. The paints are appreciated by house owners because they make mud walls more resistant to abrasion.

\section{Disadvantages}

A larger quantity of formulation is needed per house and precautions have to be taken to prevent blockage of spray nozzles by the polymerizing latex.

The insecticidal paints were Ines fly 5A IGR (Insect Growth Regulator, containing diazinon (1.5\%), chlorpyrifos (1.5\%) and pyriproxyfen $(0,063 \%)$ (insect growth regulator, IGR) as active ingredients, and Ines fly $5 \mathrm{~A}$ IGR NG containing $\alpha$-cypermethrin $(0.7 \%)$, d-alethrin (1\%) and pyriproxifen $(0,063 \%)$ as active ingredients (pyrethroid formulation). ${ }^{4}$ Both formulations are vinyl paints with an aqueous base, with the active ingredients residing within $\mathrm{CaCO}_{3}+$ resin microcapsules. The formulation allows the gradual release of the active ingredients, increasing persistence and reducing the hazard to other organisms. The microcapsules have a morphological structure consisting of an active nucleus, surrounded by a thin frame polymer that encloses the active ingredients and pigments. The product is a suspension of microcapsules that range from one to several hundred micrometers in size. Successful results forthis paint formulation have been reported for the control of mosquitoes ${ }^{5}$ and cockroaches (Periplaneta americana) (Lopez et al. unpublished results) and $T$ infestans. ${ }^{6}$

Consumer-driven disease prevention, as opposed to governmentoperated top-down programs, may have reached a crucial tipping point in many areas, suggesting a large-scale and so far, uncontested market for PPs that offers both decorative (with choice of colors) and surface protective properties in addition to vector control. It is argued that PPs could obtain universal availability relatively quickly, as the PP technology is easily adapted to the existing manufacturing, distribution, and sales networks for conventional paint. ${ }^{7}$ This critical incentive for commercial development, production, and marketing of 
PPs has already garnered the attention of multinational corporations, such as paint company Akzo Nobel and insecticide producer Bayer. In 2013, Akzo Nobel launched a PP production facility in West Africa and initiated development activities in India. Last year, Bayer signed an agreement with the PP producer, Ines fly, for distribution rights to two of their main products.

Insecticidal paints are considered suitable for urban, peri-urban, and rural communities alike. Increased urbanization and general economic development are also creating new residential patterns and affecting building practices in most disease-endemic areas. This is noted by a shift towards modern building materials, including cement, plasters, plywood, and corrugated metal, which are far better suited for paint application than traditional materials, e.g., wattle and daub. Importantly, paint adhesion, application methods, and AI activity will certainly be influenced by specific properties of both modern and traditional materials (e.g., low $\mathrm{pH}$ of cement, high porosity of wattle and daub), implying that further studies are needed for PP manufacturers to adapt their product range to the predominant building materials of a given region. ${ }^{8}$

Introduction of vectors and/or pathogens into new areas of the world, such as Aedes albopictus into southern and central Europe; Leishmania species into southern Europe, North America, and Australia; chikungunya and Zika viruses into the Americas; and, not least, the expansion and intensification of dengue virus transmission throughout the pan- and subtropical areas, is creating potential new markets for PPs. ${ }^{9}$ Insecticide resistance, in the form of physiological, biochemical, and/or behavioral resistance, presents a major problem for current pest control efforts. Increased levels of pyrethroid resistance are particularly problematic, as this class of insecticides remains the predominant choice for IRS and is exclusively used for long lasting insecticide treated nets. ${ }^{10}$ A notable feature of the PP technology is the ability to embed multiple AIs in the same PP. This includes the different classes of conventional insecticides as well as insecticide synergists and insect growth regulators. The combination of different AIs could overcome existing insecticide resistance and impede the development of new resistance traits.

\section{Conclusion}

Indeed, the human and ecological safety of current PPs should be comparable to that of existing insecticide-based interventions, given a restricted use of AIs approved by the World Health Organization's Pesticide Evaluation Scheme (WHOPES). ${ }^{11}$ However, PPs may present a different safety profile given their slow-release mechanism and prolonged activity. The need for policy and guidance in terms of safe PP production, sale, application, and disposal of PP-related items (e.g., used brushes, canisters, and out-of-date products) is obvious, if a repeat of previous experiences with poor product stewardship of vector control interventions is to be avoided. The organophosphateand pyrethroid-based insecticidal paints showed a very long residual activity, compared with the traditional spraying technique used for the application of pyrethroid insecticides in peridomestic structures of rural houses. ${ }^{12}$ The application of the paints by trained personnel of the vector control programmes could be considered as an alternative control tool in areas where the traditional methods have failed or showed low efficacy. ${ }^{13-15}$

\section{Acknowledgments}

We are grateful to teachers of Bidhan Chandra Krishi Viswavidyalaya (BCKV) for editing and correction of the manuscript.

\section{Conflict of interest}

The authors declare there is no conflict of interest.

\section{References}

1. Gopalan M. AkzoNobel thinking up a paint to contain malaria! The Hindu Business Line. India; 2014.

2. Alarico AG, Romero N, Hernandez L, et al. Residual effect of a micro-encapsulated formulation of organophosphates and piriproxifen on the mortality of deltamethrin resistant Triatoma infestans populations in rural houses of the Bolivian Chaco region. Mem Inst Oswaldo Cruz. 2010;105(6):752-756.

3. Pigott DM, Bhatt S, Golding N, et al. Global distribution maps of the leishmaniases. eLife. 2014;3:e02851.

4. Bayer, Inesfly. sign a colaboration agreement in Spain [press release]. Bayer Environmental Science. Spain; 2014.

5. Mosqueira B, Chabi J, Chandre F, et al. Efficacy of an insecticide paint against malaria vectors and nuisance in West Africa-part 2: field evaluation. Malar J. 2010;9:341

6. Gorla DE, Ortiz RV, Catala SS. Control of rural house infestation by Triatoma infestans in the Bolivian Chaco using a microencapsulated insecticide formulation. Parasit Vectors. 2015;8:255.

7. De Silva PM, Marshall JM. Factors contributing to urban malaria transmission in sub-saharan Africa: a systematic review. J Trop Med. 2012;2012:819563.

8. Mosqueira B, Duchon S, Chandre F, et al. Efficacy of an insecticide paint against insecticide-susceptible and resistant mosquitoes-part 1: laboratory evaluation. Malar J. 2010;9:340.

9. Hemingway J. The role of vector control in stopping the transmission of malaria: threats and opportunities. Philos Trans R Soc Lond B Biol Sci. 2014;369(1645):20130431

10. Acapovi-Yao G, Kaba D, Allou K, et al. Assessment of the Efficiency of Insecticide Paint and Impregnated Nets on Tsetse Populations: Preliminary Study in Forest Relics of Abidjan, Côte d'Ivoire. West African Journal of Applied Ecology. 2014;22(1):17-25.

11. Mosqueira B, Soma DD, Namountougou M, et al. Pilot study on the combination of an organophosphate-based insecticide paint and pyrethroid-treated long lasting nets against pyrethroid resistant malaria vectors in Burkina Faso. Acta Trop. 2015;148:162-169.

12. Maloney KM, Ancca-Juarez J, Salazar R, et al. Comparison of insecticidal paint and deltamethrin against Triatoma infestans (Hemiptera: Reduviidae) feeding and mortality in simulated natural conditions. $J$ Vector Ecol. 2013;38(1):6-11.

13. Amelotti I, Catala S, Gorla D. Experimental evaluation of insecticidal paints against Triatoma infestans (Hemiptera: Reduviidae), under natural climatic conditions. Parasites \& Vectors. 2009;2(1):30.

14. Anonymous. Insect-Killing Paint Rolls Out in Africa Durabilityanddesign.com. Technology Publishing Co, Pennsylvania, USA; 2013.

15. Weaver SC. Urbanization and geographic expansion of zoonotic arboviral diseases: mechanisms and potential strategies for prevention. Trends Microbiol. 2013;21(8):360-363. 